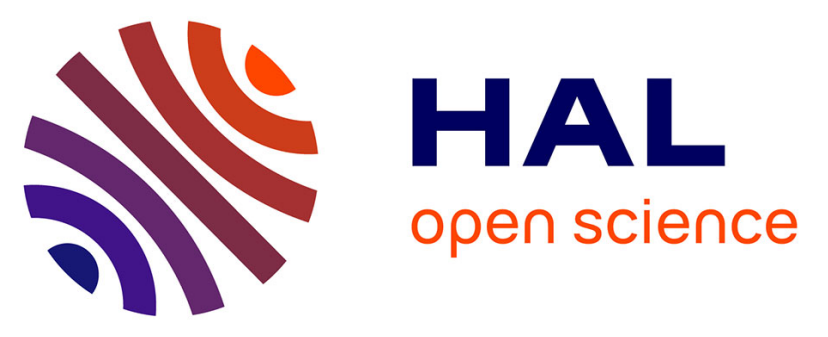

\title{
Mineral supplementation of white wheat flour is necessary to maintain adequate mineral status and bone characteristics in rats
}

Charles Coudray, Marie-Anne Verny, Jean Tressol, Christine Feillet-coudray, Noëlle Horcajada-Molteni, Christian Demigné, Yves Rayssiguier, Christian Remesy

\section{To cite this version:}

Charles Coudray, Marie-Anne Verny, Jean Tressol, Christine Feillet-coudray, Noëlle HorcajadaMolteni, et al.. Mineral supplementation of white wheat flour is necessary to maintain adequate mineral status and bone characteristics in rats. Journal of Trace Elements in Medicine and Biology, 2001, 15, pp.131-137. 10.1016/S0946-672X(01)80056-0 . hal-02674242

\section{HAL Id: hal-02674242 \\ https://hal.inrae.fr/hal-02674242}

Submitted on 19 Aug 2021

HAL is a multi-disciplinary open access archive for the deposit and dissemination of scientific research documents, whether they are published or not. The documents may come from teaching and research institutions in France or abroad, or from public or private research centers.
L'archive ouverte pluridisciplinaire HAL, est destinée au dépôt et à la diffusion de documents scientifiques de niveau recherche, publiés ou non, émanant des établissements d'enseignement et de recherche français ou étrangers, des laboratoires publics ou privés.

\section{(c)(1)}

Distributed under a Creative Commons Attribution| 4.0 International License 


\title{
Mineral supplementation of white wheat flour is necessary to maintain adequate mineral status and bone characteristics in rats
}

\author{
Charles Coudray*, Marie A. Levrat-Verny, Jean C. Tressol, Christine Feillet-Coudray, Noëlle M. Horcajada-Molteni, \\ Christian Demigné, Yves Rayssiguier and Christian Rémésy
}

Centre de Recherche en Nutrition Humaine d'Auvergne, Laboratoire Maladies Métaboliques et Micronutriments, I.N.R.A., Centre de Recherche de Clermont-Ferrand/Theix, F-63122 St-Genès-Champanelle, France.

Correspondence to: * to whom all correspondence should be addressed: Phone: (33) 473624281 ; Fax: (33) 473624638 ,

E-mail: coudray@clermont.inra.fr.

\begin{abstract}
This experiment was designed to compare the effect of ingestion of a wheat flours on mineral status and bone characteristics in rats. White flour was tested either without further mineral supplementation or with $\mathrm{Mg}, \mathrm{Fe}, \mathrm{Zn}$ and Cu supplementation. The flour diets were compared to a control purified diet. Four groups of 10 male Wistar rats each were fed one of the experimental diets for $6 \mathrm{wk}$ and mineral status and tissue retention as well as bone characteristics were determined. As expected, mineral intake, except for calcium, was significantly lesser in rats fed the white flour diet than in the other groups. The rats fed the white flour diet had the lowest food intake, weight gain, fecal excretion and intestinal fermentation. The most important result was that $\mathrm{Mg}$ and Fe status were drastically lower in rats fed the white flour diet than in those fed whole flour or control diets. The status of these both elements were significantly improved by the mineral supplementation of white flour. There were no major significant differences between mineral-supplemented white flour and whole flour groups in mineral status. Furthermore, bone mineral densities (total, metaphyseal and diphyseal) were significantly lower in rats fed white flour diet compared to the other diet groups, while no significant difference was observed between the mineralsupplemented white flour, whole flour or control diet groups. In conclusion, the present work shows clearly the importance of mineral-supplementation of white wheat flour to sustain an adequate intake of minerals. Our results indicate also that the whole wheat flour did not negatively alter mineral bioavailability, in comparison to mineral supplemented white flour. Clinical studies are still needed to confirm these rat results in human.
\end{abstract}

Key words: wheat flour, fibers, minerals, status, bone, rat

\section{Introduction}

More than $50 \%$ of the world's total food energy is supplied by the eight most common grains species (wheat, rice, corn, oat, rye, barley, millet and sorghum). They are the major source of starch together with fibers, and they also contain non-negligible amounts of proteins, minerals and vitamins (1). The grains consumed in the industrialized countries are usually subjected to various types of processing: milling, heat extraction, cooking, or other techniques which may alter the nutritional value of foods. Milling is a process that consists in separating bran and germ from the starchy endosperm in order to produce white flour. However, such a refining results in significant nutrient losses, in particular fibers, minerals and vitamins.

Abbreviations: DBMD : diaphyseal bone mineral density; DEXA : dual energy X-ray absorptiometry; MBMD : metaphyseal bone mineral density, RBC : red blood cell, SCFA : short chain fatty acid, TBMD : Total bone mineral density. 
Cereal products contribute substantially to the dietary supply of minerals, but since $60 \%$ of the minerals are present in the aleurone cells, refined white flours are drastically depleted in minerals, compared to whole flours. Moreover, mineral bioavailability could be affected by the presence of large amounts of phytate, $85 \%$ of which is localized in the aleurone layer (2). This molecule is a strong chelator of mineral ions such as $\mathrm{Ca}^{2+}, \mathrm{Zn}^{2+}$ and $\mathrm{Fe}^{3+}$ and is not readily absorbed or digested in the small intestine due to the low activity of intestinal phytase in humans (3-4). The advantage of consuming whole cereals rather than refined cereals has often been questioned (5-6). The potentially anti-nutritive effects of phytic acid have been mostly studied using diets supplemented to the same level of minerals (7-8).

Except for calcium and sodium, a cereal like wheat can fulfill any mineral requirement but it is rich in fibers and phytic acid $(0.32 \%$ of the whole grain) (1). It was thus of interest to compare the actual mineral bioavailability in rats fed diets in which the cereal product supplied was either white wheat flour supplemented or not in minerals, or whole wheat flour without any mineral supplement except for calcium carbonate and sodium chloride. The present study indicates that whole wheat flour represents a good source of available minerals, equal to that from the refined white flour supplemented in minerals.

\section{Material and Methods}

\section{Materials and reagents}

Wheat flours were purchased from a local Massagette Mill, Massagette, France. Casein was purchased from Louis François, St Maur, France. $\mathrm{CaCO}_{3}$ was purchased from Sigma Chemical, St Louis, MO. NaCl was purchased from Merck, Darmstadt, Germany. Peanut oil was purchased from Brendani, Clermont-Ferrand, France. All other chemicals were of the highest quality available. Distilled water was used throughout.

\section{Animals and diets}

Forty male Wistar rats (IFFA-CRED0, L'Arbresle, France) that initially weighed $160 \mathrm{~g}$ were adapted to four experimental purified diets distributed as a moistened powder for six weeks. The control diet contained $(\mathrm{g} / \mathrm{kg})$ wheat starch : 650, casein : 200, peanut oil : 50, fibers (cellulose): 50, mineral mixture: 35 , vitamin mixture: 10, DL-methionine : 3 , Choline bitartrate : 2 . The one whole flour and the two white flour diets contained $87.5 \%$ of a French variety (Soisson, Soft Red Winter class) wheat flour (white or whole), $6 \%$ casein, $5 \%$ peanut oil, and $0.75 \% \mathrm{CaCO}_{3}$, and $0.7 \% \mathrm{NaCl}$. One of the two white flour diets was supplemented with $\mathrm{Mg}, \mathrm{Fe}, \mathrm{Zn}$ and $\mathrm{Cu}$ to reach the levels of minerals present in the whole flour diet. The mineral composition of these diets is shown in the Table 1 . No vitamins were added because wheat flour provided sufficient amounts to meet essential requirements (9). The rats were housed two per cage (wire bottomed to limit coprophagy) and maintained in controlled temperature rooms $\left(22^{\circ}\right)$ with the dark period from 20.00 to 08.00 . Food consumption and growth rate were measured twice weekly. During the last five days, the rats were transferred to metabolic cages (one rat per cage) and the feces and urine of each rat were collected. The rats were maintained and handled in accordance with the recommendations of the Institutional Ethics Committee of the INRA (Clermont-Ferrand, France).

\section{Sampling procedures}

Rats were killed at the end of the dark period (09.00). They were anaesthetized with sodium pentobarbital (40 $\mathrm{mg} / \mathrm{kg}$ ) and maintained on a hot plate at $37^{\circ}$. Blood was drawn into heparinized syringes from the abdominal aorta (5-10 $\mathrm{mL})$. Liver, femur and tibia were also sampled. Blood from each rat was placed in a plastic tube containing heparin and centrifuged at $10000 \mathrm{~g}$ for $2 \mathrm{~min}$. After centrifugation, plasma was removed and kept at $4^{\circ}$ for analysis. After blood sampling, the cecum with content was removed and weighed (total cecal weight). Cecal contents were transferred into 2 microfuge tubes; one was

Table 1. Fiber and phytic acid contents and mineral composition of experimental diets.

\begin{tabular}{|c|c|c|c|c|c|}
\hline & Control & White Flour ${ }^{1}$ & Whole Flour ${ }^{1}$ & Adjusted White Flour² & AIN Recommendation \\
\hline \multicolumn{6}{|c|}{$\mathrm{g} / \mathrm{kg}$} \\
\hline Fiber & 50 & 20.1 & 92.5 & 20.1 & \\
\hline Phytic acid & 0 & 0.24 & 0.82 & 0.24 & \\
\hline Calcium & 5.30 & 4.54 & 4.43 & 4.35 & 5.0 \\
\hline Phosphorus & 4.42 & 1.87 & 3.46 & 3.70 & 3.0 \\
\hline Magnesium & 1.31 & 0.23 & 0.95 & 1.03 & 0.50 \\
\hline $\mathrm{P} / \mathrm{Ca}$ ratio $(\mathrm{M} / \mathrm{M})$ & 1.08 & 0.53 & 1.01 & 1.10 & 0.78 \\
\hline \multicolumn{6}{|c|}{$\mathrm{mg} / \mathrm{kg}$} \\
\hline Iron & 29.1 & 15.2 & 26.6 & 24.2 & 35 \\
\hline Zinc & 47.0 & 9.5 & 22.9 & 29.7 & 30 \\
\hline Copper & 6.7 & 1.7 & 3.9 & 5.3 & 6.0 \\
\hline
\end{tabular}

${ }^{1}$ These flour diets were supplemented with calcium carbonate and sodium chloride.

2 This flour diet was supplemented with calcium carbonate and sodium chloride, and with magnesium oxide, iron citrate, zinc chloride and copper chloride. 
immediately frozen at $-20^{\circ}$ and the cecal content $\mathrm{pH}$ was measured in the other one. The cecal wall was flushed clean, blotted and weighed (cecal wall weight).

\section{Analytical procedures}

Phytic acid level was measured in the flours by a colorimetric procedure based on the reaction between ferric ion and sulfosalicylic acid, as described by Latta \& Eskin (10). Short Chain Fatty Acids (SCFA) were measured by gas-liquid chromatography on an aliquot of supernatants of cecal contents $\left(20,000 \times g, 10 \mathrm{~min}\right.$ at $\left.4^{\circ}\right)(11)$. The SCFA cecal pool was calculated as follows: Cecal pool $(\mathrm{mmol})=$ cecal concentration $(\mu \mathrm{mol} / \mathrm{l}) \times$ cecal water content weight $(\mathrm{g})$. Transferrin saturation percent and plasma iron were determined using Ferrimat-Kit and TIBC additif from Bio Mérieux (Lyon, France).

$\mathrm{Mg}$ and $\mathrm{Ca}$ were determined after mineralization of tissues, food and feces samples $\left(10 \mathrm{~h}\right.$ at $\left.500^{\circ}\right)$. The resulting residues were extracted with $5 \mathrm{~mol} / \mathrm{L} \mathrm{HCl}$ and made up to an appropriate volume with $1 \mathrm{~g} / \mathrm{l}$ lanthanum chloride solution. To determine $\mathrm{Fe}, \mathrm{Zn}$ and $\mathrm{Cu}$ levels in liver, tibia, food and feces, 0.25 to $0.5 \mathrm{~g}$ of dried samples were dry-ached $(10 \mathrm{~h}$ at $\left.500^{\circ}\right)$ and then extracted at $130^{\circ}$ in $\mathrm{HNO}_{3} / \mathrm{H}_{2} \mathrm{O}_{2}(2 / 1)$ (Merck, Suprapur) until discoloration; final dilution was made in $0.5 \mathrm{M} \mathrm{HNO}_{3}$. Ca and $\mathrm{Mg}$ concentrations were measured after a 50 -fold dilution of plasma in lanthanum chloride solution. the other trace elements were measured after a 5-fold plasma dilution in $\mathrm{HCl}$ and tri-chloroacetic acid for protein elimination. Mineral concentrations were determined by atomic absorption spectrophotometry (PerkinElmer 420, Norwalk, (T) in an acetylene-air flame at the following wavelengths : 422 (Ca), 285 (Mg), 248 (Fe), 214 $(\mathrm{Zn})$ and $325(\mathrm{Cu})$. A nebuliser with high sensitivity was used for trace element determinations. Appropriate quality controls were run with each set of measurements.

\section{Determination of bone characteristics}

Femoral mechanical testing: The mechanical resistance of femoral bones was determined using a three point bending test as previously described (12). Thus, the femoral failure load and Young modulus were determined.

Bone mineral density: Dual energy X-ray absorbiometry (DEXA) measurements were made with a Hologic QDR-4500 A X-ray bone densitometer (Hologic France, Massy, France). Total femoral bone mineral density (TBMD) was determined. In addition, the bone mineral densities of two subregions, one corresponding to the proximal metaphyseal zone (MBMD) which is rich in calcaneus bone, and the other to diaphyseal zone (DBMD) which is rich in cortical bone, were also measured as previously described (13).

\section{Statistical analysis}

Standard procedures were used to calculate means and standard deviation (SD). Results were compared by one-way analysis of variance (ANOVA) using Instate software. The analysis of variance test was followed by a student-Newman-Keuls multiple comparisons test. Because ANOVA test assumes that standard deviations are equal, the non parametric Kruskal-Wallis test was applied when the difference among standard deviations is significant. Differences were considered as significant between groups when $p<0.05$.

\section{Results}

\section{Diet analyses and animal growth}

The chemical analysis showed that the whole flour diet, compared to the white flour diet was almost 3-fold higher in $\mathrm{Mg}$, and about $100 \%$ higher in $\mathrm{Zn}, \mathrm{Fe}$, and $\mathrm{Cu}$. Consequently, the daily supply in $\mathrm{Mg}, \mathrm{Fe}, \mathrm{Cu}$ and $\mathrm{Zn}$ was higher in rats fed whole flour than in those fed white flour, since both food intake and mineral density were higher in rats fed the former diet. The supplementation of white flour with $\mathrm{Mg}, \mathrm{Fe}, \mathrm{Zn}$ and $\mathrm{Cu}$ improved the daily supply of these minerals, to meet the dietary recommendation intakes of minerals in rats.

As shown in figure 1, body growth was faster in animals receiving the control diet than in the other animals. Rats receiving the white flour diet had a significantly slower growth rate compared to the other groups. Moreover, the white flour diet was consumed in significantly smaller quantity and the weight gain of rats fed this diet was significantly lower $(-38 \%)$ than that of rats fed the whole flour diet (table 2). However, no clinical deficiency sign was noted in rats fed the white flour diet.

\section{Fecal and cecal variables}

As expected, white flour ingestion, supplemented or not in minerals, was accompanied by a significant decrease in the amount of feces compared to whole flour or control diets groups (results not shown). In addition, the cecal SCFA pool was significantly higher in the whole wheat flour group compared to white flour group, resulting in a significantly lower cecal pH. However, the cecal content and cecal wall weights were not significantly different between whole flour and white flour diet groups. The mineral supplementation of white flour markedly increased the cecal content weight and the cecal SCFA pool, compared to the white flour group (Table 2).

\section{Bone characteristics}

White flour ingestion elicited a significantly lesser bone resistance (about $-25 \%$ ), proximal metaphyseal and diaphyseal bone mineral densities and total bone mineral density, in comparison to rats fed the control or the whole

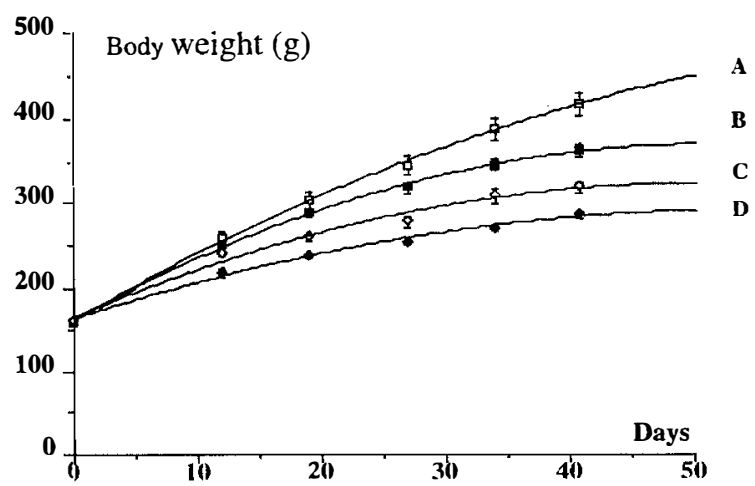

Figure 1. Effect of experimental diets on animal growth rate Values are given as mean $\pm S D,(n=10)$. Experimental diets: A : Control; B : Whole wheat flour; C : White wheat flour supplemented with minerals; and $\mathrm{D}:$ White wheat flour 
flour diets (table 3). The supplementation of white flour with minerals was efficacious to normalize the bone characteristics, which became statistically similar to those observed in the control and the whole flour groups.

\section{Ca and $\mathrm{Mg}$ status}

The Ca level was similar in the three experimental diets, but $20 \%$ higher in the control diet. Consequently, Ca status (urinary and bone $\mathrm{Ca}$ ) did not differ in the different groups, and no negative effect of the whole flour was noted. However, significantly greater plasma Ca level was observed in the white flour group compared to the other diet groups. Paradoxically, tibia dry weight and its mechanical resistance were significantly diminished in the white flour group, in comparison with the other groups (tables 3,4 ). Mg intake was $80 \%$ lower in rats fed the white flour diet than in those fed the other diets. Consequently, all $\mathrm{Mg}$ markers (plasma, RBC, urine and tibia) were significantly lower in the rats fed the white flour diet for 6 wk compared to other groups. The mineral supplementation of white flour with $\mathrm{Mg}$ significantly improved the $\mathrm{Mg}$ status to that of the control or the whole flour groups (Table 4).

\section{Trace element status}

The daily Fe intake from white flour was half of that from whole flour. Consequently, plasma Fe and transferrin saturation percentage as well as Fe tissue levels (liver and tibia) in rats fed white flour diet were twice as low as in those adapted to whole flour or control diets (table 5).
The mineral supplementation of white flour with Fe significantly improved the Fe status, to reach that of the control or the whole flour groups (Table 5).

Finally, $\mathrm{Zn}$ or $\mathrm{Cu}$ intakes were more than double in rats consuming the whole flour diet, compared to the white flour diet. The levels of $\mathrm{Zn}$ in the plasma, in RBC and in liver were not significantly different among the four experimental groups (Table 5). However, urine and tibia levels of $\mathrm{Zn}$ were significantly higher in the white flour groups than in the control or the whole flour groups. Plasma Cu level was slightly but significantly lower in the mineral supplemented white flour group compared to control or whole flour diets groups, whereas liver Cu level was not significantly different among the four experimental groups (Table 5).

\section{Discussion}

The literature concerning the impact of whole flour, rich in dietary fibers, on mineral bioavailability is discordant. Negative effects on mineral bioavailability have been frequently ascribed to foods rich in dietary fibers or their associated compounds $(3,5,8,14)$. This is why many nutritional recommendations advise against intake of large amounts of unrefined cereal products. Consequently, the grains consumed in the industrialized countries are usually subjected to various types of processing, in particular the milling process. Unfortunately, such a refining results in substantial nutrient losses (fibers, vitamins and

Table 2. Daily weight gain, food intake, fecal excretion and fecal variables in rats fed for six weeks control or white wheat flour or whole wheat flour adjusted or not for minerals ${ }^{1,2}$

\begin{tabular}{lcccc}
\hline & Control & White Flour & Whole Flour & Adjusted White Flour \\
\hline Weight gain, g/d & $6.4 \pm 0.2 \mathrm{a}$ & $3.1 \pm 0.1 \mathrm{~d}$ & $5.1 \pm 0.1 \mathrm{~b}$ & $3.9 \pm 0.1 \mathrm{c}$ \\
Food intake, g/d & $25.1 \pm 0.6 \mathrm{a}$ & $19.4 \pm 0.6 \mathrm{C}$ & $22.2 \pm 0.5 \mathrm{~b}$ & $20.3 \pm 0.4 \mathrm{C}$ \\
Feed efficiency ratio & $0.25 \pm 0.01 \mathrm{a}$ & $0.16 \pm 0.01 \mathrm{c}$ & $0.23 \pm 0.01 \mathrm{a}$ & $0.19 \pm 0.01 \mathrm{~b}$ \\
& & & & \\
Cecal content, g & $2.93 \pm 0.22 \mathrm{~b}$ & $2.08 \pm 0.19 \mathrm{c}$ & $2.60 \pm 0.16 \mathrm{~b}, \mathrm{c}$ & $3.64 \pm 0.35 \mathrm{a}$ \\
Cecal wall, g & $0.93 \pm 0.07 \mathrm{a}$ & $0.95 \pm 0.04 \mathrm{a}$ & $1.12 \pm 0.07 \mathrm{a}$ & $1.12 \pm 0.26 \mathrm{a}$ \\
cecal pH & $7.28 \pm 0.05 \mathrm{a}$ & $6.97 \pm 0.07 \mathrm{~b}$ & $6.57 \pm 0.13 \mathrm{C}$ & $6.73 \pm 0.10 \mathrm{c}$ \\
Cecal SCFA, $\mu \mathrm{mol}$ & $393 \pm 38 \mathrm{a}$ & $225 \pm 17 \mathrm{~b}$ & $426 \pm 53 \mathrm{a}$ & $390 \pm 40 \mathrm{a}$ \\
\hline
\end{tabular}

${ }^{1}$ Values are given as mean $\pm S D,(n=10)$.

${ }^{2}$ Means in a row not sharing a superscript are significantly different $(p<0.05)$.

Table 3. Bone characteristics in rats fed for six weeks control or whole wheat flour or white wheat flour adjusted or not for minerals ${ }^{1,2}$.

\begin{tabular}{lcccc}
\hline & Control & White Flour & Whole Flour & adjusted White Flour \\
\hline Femoral failure load, N & $101 \pm 1.5 \mathrm{a}$ & $77.3 \pm 1.0 \mathrm{~b}$ & $96.0 \pm 1.0 \mathrm{a}$ & $95.6 \pm 0.82 \mathrm{a}$ \\
Young Modulus, MPa & $3065 \pm 67 \mathrm{a}$ & $2324 \pm 53 \mathrm{~b}$ & $3155 \pm 33 \mathrm{a}$ & $3036 \pm 44 \mathrm{a}$ \\
Metaphyseal BMD, mg/cm2 & $209 \pm 1.0 \mathrm{a}$ & $182 \pm 1.3 \mathrm{~b}$ & $213 \pm 0.7 \mathrm{a}$ & $216 \pm 1.3 \mathrm{a}$ \\
Diaphyseal BMD, mg/cm2 & $174 \pm 1.3 \mathrm{a}$ & $148 \pm 1.2 \mathrm{~b}$ & $177 \pm 1.0 \mathrm{a}$ & $182 \pm 1.0 \mathrm{a}$ \\
Total BMD, mg/cm2 & $187 \pm 0.4 \mathrm{~b}$ & $169 \pm 1.3 \mathrm{c}$ & $198 \pm 1.1 \mathrm{a}$ & $201 \pm 0.8 \mathrm{a}$ \\
Total BMC, mg & $344 \pm 3.0 \mathrm{~b}$ & $282 \pm 3.1 \mathrm{c}$ & $385 \pm 3.4 \mathrm{a}$ & $383 \pm 2.4 \mathrm{a}$ \\
\hline
\end{tabular}

${ }^{1}$ Values are given as means \pm SD $(n=10)$.

${ }^{2}$ Means in a row not sharing a superscript are significantly different $(p<0.05)$. DBMD : diaphyseal bone mineral density; MBMD : metaphyseal bone mineral density, TBMD : Total bone mineral density. 
minerals). For example, the mineral level in the whole wheat flour used in the present study was 1 to 2 fold higher than in the refined white wheat flour. Thus, it would be important to evaluate during a long period (several months) the impact of such refined products on mineral status and to check whether unrefined products can modify this status, especially when these products represent an important source of minerals.

The diets used in the present study differed in several respects including fiber, phytic acid and mineral concentrations (except for $\mathrm{Ca}$ and $\mathrm{Na}$ ). The experimental diets ensured a well balanced supply of proteins, lipids and carbohydrates. The whole flour and the mineral supplemented white flour diets met several of the American Institute of Nutrition (AIN) mineral recommendations whereas the mineral levels in the white wheat flour diet were largely lower than the recommended levels.
The results of the present experiment showed clearly that the ingestion of white flour, deficient in minerals, led to overt deficiency in $\mathrm{Mg}$ and Fe. We also showed that the supplementation of the white flour with minerals was efficacious to improve the mineral status which therefore attained that observed in the control or the whole flour diet groups. Altogether, this experiment showed that unrefined flour may be a good source of minerals, equal to that from refined flour supplemented with minerals. Moreover, it must be kept in mind that numerous other functionally active constituents are present in the unrefined flour.

Because wheat flours are generally poor in $\mathrm{Na}$ and $\mathrm{Ca}$, the three experimental flour diets were supplemented with these cations. Ca intake was thus similar in the four experimental groups. In spite of the differences in the characteristics of the tested flours, the urine and bone

Table 4. Calcium and magnesium concentrations in rats fed for six weeks control or whole wheat flour or white wheat flour adjusted or not for minerals ${ }^{1,2}$.

\begin{tabular}{lcccc}
\hline & Control & White Flour & Whole Flour & Adjusted White Flour \\
\hline Calcium & & & & \\
Plasma, mmol/L & $2.44 \pm 0.03 \mathrm{~b}$ & $2.59 \pm 0.05 \mathrm{a}$ & $2.34 \pm 0.03 \mathrm{~b}$ & $2.37 \pm 0.04 \mathrm{~b}$ \\
Urine, $\mu \mathrm{mol} / \mathrm{d}$ & $53.1 \pm 8.5 \mathrm{a}$ & $45.1 \pm 5.2 \mathrm{a}$ & $51.6 \pm 9.2 \mathrm{a}$ & $66.3 \pm 6.9 \mathrm{a}$ \\
Tibia, mmol/g dry w & $6.08 \pm 0.10 \mathrm{a}$ & $6.13 \pm 0.05 \mathrm{a}$ & $6.01 \pm 0.08 \mathrm{a}$ & $5.99 \pm 0.10 \mathrm{a}$ \\
Tibia weight, mg dry w & $332 \pm 13 \mathrm{a}$ & $265 \pm 9 \mathrm{~b}$ & $320 \pm 11 \mathrm{a}$ & $327 \pm 11 \mathrm{a}$ \\
& & & & \\
Magnesium & & & & $0.95 \pm 0.03 \mathrm{a}$ \\
Plasma, mmol/L & $0.87 \pm 0.02 \mathrm{a}$ & $0.58 \pm 0.04 \mathrm{~b}$ & $0.02 \mathrm{a}$ & $2.28 \pm 0.03 \mathrm{a}$ \\
RBC, mmol/l & $2.14 \pm 0.05 \mathrm{a}$ & $1.74 \pm 0.04 \mathrm{~b}$ & $2.28 \pm 0.03 \mathrm{a}$ & $0.22 \pm 0.01 \mathrm{a}$ \\
Urine, mmol/d & $0.21 \pm 0.02 \mathrm{a}$ & $0.09 \pm 0.01 \mathrm{~b}$ & $0.19 \pm 0.03 \mathrm{a}$ & $184 \pm 2.9 \mathrm{a}$
\end{tabular}

${ }^{1}$ Values are given as means \pm SD $(n=10)$.

2 Means in a row not sharing a superscript are significantly different $(p<0.05)$.

Table 5. Iron, zinc and copper concentrations in rats fed for six weeks control or whole wheat flour or white wheat flour adjusted or not for minerals ${ }^{1,2}$.

\begin{tabular}{|c|c|c|c|c|}
\hline & Control & White Flour & Whole Flour & Adjusted White Flour \\
\hline \multicolumn{5}{|l|}{ Iron: } \\
\hline Plasma, $\mu \mathrm{mol} / \mathrm{L}$ & $33.3 \pm 2.9 a$ & $10.3 \pm 1.6 \mathrm{c}$ & $21.9 \pm 1.2 b$ & $29.1 \pm 1.7 \mathrm{a}$ \\
\hline Liver, $\mu \mathrm{mol} / \mathrm{g}$ dry w. & $3.87 \pm 0.14 b$ & $2.20 \pm 0.16 c$ & $5.61 \pm 0.45 a$ & $5.07 \pm 0.22 a$ \\
\hline Tibia, $\mu \mathrm{mol} / \mathrm{g}$ dry w. & $0.85 \pm 0.06 a$ & $0.70 \pm 0.03 a$ & $0.82 \pm 0.04 a$ & $0.86 \pm 0.05 a$ \\
\hline Transferrin saturation (\%) & $47.3 \pm 4.7 \mathrm{a}$ & $12.0 \pm 2.0 \mathrm{~b}$ & $36.8 \pm 3.9 a$ & $46.2 \pm 3.9 \mathrm{a}$ \\
\hline Hemoglobin, g/L & $138 \pm 6 a$ & $122 \pm 4 b$ & $146 \pm 3 a$ & $141 \pm 2 a$ \\
\hline \multicolumn{5}{|l|}{ Zinc: } \\
\hline Plasma, $\mu \mathrm{mol} / \mathrm{L}$ & $22.0 \pm 0.8 a$ & $24.8 \pm 0.9 a$ & $22.6 \pm 0.8 a$ & $23.4 \pm 0.3 a$ \\
\hline $\mathrm{RBC}, \mu \mathrm{mol} / \mathrm{l}$ & $124 \pm 5.0 \mathrm{a}$ & $124 \pm 4.9 a$ & $128 \pm 2.6 \mathrm{a}$ & $131 \pm 3.2 \mathrm{a}$ \\
\hline Urine, $\mu \mathrm{mol} / \mathrm{d}$ & $0.11 \pm 0.02 b$ & $0.18 \pm 0.02 \mathrm{a}$ & $0.08 \pm 0.02 b$ & $0.22 \pm 0.02 \mathrm{a}$ \\
\hline Tibia, $\mu \mathrm{mol} / \mathrm{g}$ dry w. & $3.01 \pm 0.04 \mathrm{c}$ & $3.46 \pm 0.05 b$ & $3.17 \pm 0.10 c$ & $3.75 \pm 0.08 a$ \\
\hline Liver, $\mu \mathrm{mol} / \mathrm{g}$ dry w. & $1.38 \pm 0.04 \mathrm{a}$ & $1.43 \pm 0.06 a$ & $1.39 \pm 0.03 a$ & $1.46 \pm 0.03 a$ \\
\hline \multicolumn{5}{|l|}{ Copper: } \\
\hline Plasma, $\mu \mathrm{mol} / \mathrm{L}$ & $16.1 \pm 0.8 a$ & $15.8 \pm 0.5 a$ & $14.7 \pm 0.3$ a.b & $14.1 \pm 0.4 b$ \\
\hline Liver, $\mu \mathrm{mol} / \mathrm{g}$ dry w. & $0.24 \pm 0.01 \mathrm{a}$ & $0.26 \pm 0.03 a$ & $0.19 \pm 0.01 a$ & $0.22 \pm 0.01 \mathrm{a}$ \\
\hline
\end{tabular}

${ }^{1}$ Values are given as means \pm SD $(n=10)$.

${ }^{2}$ Means in a row not sharing a superscript are significantly different $(p<0.05)$. 
levels of Ca were similar in the four studied groups. However, hypercalcaemia was observed in rats receiving the white flour diet. This hypercalcaemia may be simply the result of the severe $\mathrm{Mg}$ deficiency which is known to induce an hypercalcaemia in rats (15). The fact that $\mathrm{Ca}$ status remained unchanged in rats receiving the whole flour diet or the mineral supplemented white flour diet is not surprising, since the phytic acid/Ca ratio was low (0.23). The bone Ca level confirms that the use of whole flour diet had no negative effects on Ca metabolism compared to the control or to the mineral supplemented white flour diet groups. In a previous study, it has been shown that $\mathrm{Ca}$ absorption from whole or white flour diets containing the same levels of Ca was not different in rats (16).

The results of the present study show clearly that white flour ingestion accompanies with a severe $\mathrm{Mg}$ deficiency, whereas whole flour, rich in dietary fibers and in $\mathrm{Mg}$, appeared to be a very interesting source of available $\mathrm{Mg}$, ensuring a good $\mathrm{Mg}$ status reflected by both plasma and tibia Mg levels. These results are in good agreement with a previous study showing that $\mathrm{Mg}$ absorption was better from whole flour than white flour diets in rats (14). The supplementation of white flour with $\mathrm{Mg}$ normalized the Mg status (plasma, RBC and urine) which became similar to that observed in the control and the whole flour groups. Whole flour was not less efficient on $\mathrm{Mg}$ status than supplemented white flour. The principal route of $\mathrm{Mg}$ absorption in the distal part of the digestive tract is the passive para-cellular pathway whereas active trans-cellular transport is relatively unimportant (17). Thus, concentration and solubility of $\mathrm{Mg}$ and intestinal epithelium permeability are probably the principal determinants of $\mathrm{Mg}$ absorption (18). Cereal products are good sources of $\mathrm{Mg}$, and a slightly acidic $\mathrm{pH}$ in the cecum can promote an effective solubilization of $\mathrm{Mg}$ (19).

Calcium and $\mathrm{Mg}$, together with phosphorus are the major constituents of bone ash. The bone quality is directly related to the amount and the bioavailability of these minerals in the diet. In the present study, the determination of femoral characteristics on the left femur of rat indicated that the white flour ingestion decreased significantly the bone mineral density which is an important factor in determining bone strength and known to be strongly associated with fracture risk. The unaltered $\mathrm{Ca}$ status may appear in disagreement with the femoral bone characteristics in the studied groups. Indeed, these bone characteristics are dependent on many factors such $\mathrm{Ca}$ status, dietary P-Ca ratio and status of the other dietary minerals, in particular $\mathrm{Mg}$. $\mathrm{Mg}$ participates in the normal formation and remodeling of bone and its status influence the biomechanical function of bone (20). $60 \%$ of $\mathrm{Mg}$ of the organism is concentrated in the bone and hence a severe deficiency in $\mathrm{Mg}$ may seriously negatively affect the bone characteristics. The supplementation of white flour with minerals, especially $\mathrm{Mg}$, allowed to normalize the bone characteristics which became close to those observed in animals fed control and whole flour diets. The effects of the supplemented white flour and the whole flour were not significantly different, which means that whole flour ingestion was without negative effects on bone characteristics in rats, in contrast to white flour ingestion.

The daily intake of $\mathrm{Fe}, \mathrm{Zn}$ and $\mathrm{Cu}$ was significantly lower in rats fed the white flour diet than in those fed the whole flour diet. Supplementation of white flour diet with minerals afforded a mineral intake close to that observed in control or whole flour diet groups. The whole flour diet contained twice more Fe than the white flour diet did, translated in a significant decrease in Fe status with the white flour diet ingestion. Indeed, the present results indicate that rats fed the white flour diet have plasma, liver and tibia concentrations of Fe twice lower than those found in rats fed whole flour. Rats fed the white flour diets showed also a significant decrease in hemoglobin level $(-16 \%)$ in comparison to the rats fed whole flour, indicating an anemia in these rats. A good intestinal absorption of $\mathrm{Fe}$ in the lower part of the digestive tract could probably explain this effect, as a result of luminal $\mathrm{pH}$ lowering and micro flora activity (21). Indeed, in a previous study, Fe absorption was found more effective from whole flour than from white flour diets in rats (14). Because Fe homeostasis is controlled by absorption, an increase in Fe absorption by more than $100 \%$ may be responsible for this rise of plasma $\mathrm{Fe}$ in rats fed the whole flour diet. This is one unique aspect of Fe metabolism which takes place in a closed circuit. In fact, the Fe pool is subjected to a permanent renewal and this process is nearly independent of external Fe. Thus, Fe deficiency can develop when intake is dramatically low, and Fe overload can also occur when the daily absorbed amount of Fe is increased $(22,23)$. The supplementation of white flour with Fe allowed to normalize the Fe status which became close to that observed in animals fed whole flour or control diets.

In spite the fact that rats fed for six weeks the white flour diet, 50\% lower in $\mathrm{Zn}$ and $\mathrm{Cu}$ content than the other diets, the present results indicate that $\mathrm{Zn}$ or $\mathrm{Cu}$ status were not significantly modified in rats receiving the white flour diet in comparison to those of rats receiving the control or the whole flour diet. In addition, the supplementation of white flour with $\mathrm{Zn}$ and $\mathrm{Cu}$ did not elicit any effect on these parameters. Generally, $\mathrm{Zn}$ and Cu homeostasis is well controlled, and remains constant over a wide range of dietary intake levels (24). Indeed, the endogenous excretion of $\mathrm{Zn}$ or $\mathrm{Cu}$ in the feces is very regulated according to the dietary intake. Only very low or very high dietary intakes for long periods cause the regulatory mechanisms to become overloaded resulting either in a depletion or an accumulation of the element in the body. Therefore, it could be interesting to study for a longer time the effect of such flours on $\mathrm{Zn}$ and $\mathrm{Cu}$ status.

Negative effects of dietary fibers and phytic acid by mineral complexing have been often studied by adding fibers or phytic acid directly in diets. Such an experimental protocol fails to take into account the mineral content of fiber-rich products, as in the present experimental diets. Such products are known to be highly rich in minerals (25). It is well established that rats have a high capacity to hydrolyze phytic acid, compared to humans who have very low intestinal phytase activity (26). However, when wheat is eaten in completely leavened bread, 
more than $50 \%$ of phytic acid is already destroyed (27). Furthermore, it is noteworthy that the maintain of the phytase activity in cereal products may allow partial hydrolysis of dietary phytate in the stomach, improving the bioavailability of minerals.

In conclusion, even if rat is not a perfect model to evaluate mineral bioavailability for man, the results of this experiment show clearly that whole flour was practically as effective on mineral status as white flour adequately supplemented with minerals. The ingestion of unrefined products was not accompanied by negative effects on mineral status, and then can be encouraged. Moreover, recent epidemiological and clinical studies have shown interest in increasing the consumption of phytic acid-rich products in preventive nutrition. The possible negative effects of such products on mineral status can be less important when these products are taken together with the other components of the meal. It is thus wise to promote the consumption of whole grains rather than of purified cereal products, to minimize the loss of functionally active constituents of grains during industrial processing and to optimize the mineral status in humans. Human studies are still needed to confirm these results in rats.

\section{Acknowledgements}

The authors would like to thank Richard TAYLOR for editorial assistance, and Claudine LAB, Elyett GUEUX and Pierre LAMBY for their technical assistance.

\section{References}

1. O'Dell, B.L., De Borland, A.R. and Koirtyohann, S.R. Distribution of phytate and nutritionally important elements among morphological components of cereal grains J. Agric. Food Chem. (1972); 20: 718-720.

2. Betschart, A.A. Nutritional quality of wheat and wheat foods. In : Pomeranz, Y., ed. Wheat: Chemistry and Technology; 3rd edition, St. Paul, MN: American Association of Cereal Chemistry. (1988); pp 91-130.

3. McCance, R. and Widdowson, E. Mineral metabolism of healthy adults on white and brown bread dietaries. Amer. J. Physiol. (1942); 101: 44-85.

4. Harland, B. and Morris, E. Phytate: a good or a bad food component?. Nutr. Res. (1995); 15: 733-754.

5. Reinhold, J., Faradji, B., Abadi, P. and Ismai-Beigi, F. Decrease absorption of calcium, magnesium, zinc and phosphorus by humans due to increased fiber and phosphorus consumption as wheat bread. J. Nutr. (1976); 106: 493-503.

6. Sandstead, H. Fiber, phytic acid and mineral metabolism. Nutr. Rev. (1992); 50: 30-31.

7. Rimbach, G., Pallauf, J., Brandt, K. and Most, E. Effect of phytic acid and microbial phytase on $\mathrm{Cd}$ accumulation, $\mathrm{Zn}$ status and apparent absorption of $\mathrm{Ca}, \mathrm{P}, \mathrm{Zn}, \mathrm{Cu}$ and $\mathrm{Mn}$ in growing rats. Ann. Nutr. Metabol. (1995); 39: 361-370.

8. Saha, P., Weaner, C. and Mason, A. Mineral bioavailability in rats from intrinsically labeled whole wheat flour of various phytate levels J. Agric. Food Chem. (1994); 42: 2531-2535.

9. Salovaara, H. In: Macrea, R., Robinson, R.K. and Sadler, MJ. Ed. Cereals Encyclopedia of food science, food technology and nutrition. Academic Press, London, U.K. (1993); pp $2: 768-772$.
10. Latta, M. and Eskin, M. Simple and rapid colorimetric method for phytate determination. J. Agric. Food Chem. (1980); 8: 1313-1315.

11. Demigné, C., Rémésy, C. and Rayssiguier, Y. Effects of fermentable carbohydrates on volatile fatty acids, ammonia and mineral absorption in the rat cecum. Reprod. Nutr. develop. (1980); 20: 1351-1359.

12. Pastoureau, P., Chomel, A. and Bonnet, J. Specific evaluation of localized bone mass and bone loss in the rat using dual energy X-ray absorptiometry subregional analysis. Osteop. Intern. (1995); 5: 143-149.

13. Horcajada-Molteni, M.N., Davidco, M.J., Coxam, V., Lebecque, P., Dominguez, B., Ritz, P., Culiolo, J. and Barlet, J.B. Treadmill running starting 3 months after orchidectomy restores femoral bone mass in rats. Europ. J. Appl. Physiol. (1999); 79: 251-259.

14. Bagheri, S. and Gueguen, L. Influence des fibres alimentaires sur le métabolisme minéral. Cah. Nutr. Diét. (1983); 18: $77-83$.

15. Rayssiguier, Y. and Larvor, P. Mineral bone composition and some elements of calcium metabolism in magnesium-deficient growing rats. Ann. Biol. Animal Biochem. Biophy. (1978); 18: 157-166.

16. Levrat-Verny, M.A., Coudray, C., Bellanger, J., Walter, L.H., Demigné, C., Rayssiguier, Y. and Rémésy, C. Rapid communication : Whole wheat flour ensures higher mineral absorption and bioavailability that white wheat flour in rats. Br. J. Nutr. (1999); 82: 17-21.

17. Hardwick, L., Jones, M., Brautbar, N. and Lee, D. Site and mechanism of intestinal magnesium absorption. Miner. Electrolytes Metabol. (1990); 16: 174-180.

18. Karbach, U. and Rummel, W. Cellular and para-cellular magnesium transport across the terminal ileum of the rat and its interaction with the calcium transport. Gastroenterology (1990); 98: 985-992.

19. Younès, H., Demigné, C. and Rémésy, C. Acidic fermentations in the cecum increases absorption of calcium and magnesium in the large intestine of the rat. Br. J. Nutr. (1996); 75: 301-314.

20. Boskey, A.L., Rimnac, C.M., Bansal, M., Federman, M., Lian, J. and Boyan, B.D. Effect of short-term hypomagnesemia on the chemical and mechanical properties of rat bone. $\mathrm{J}$. Orthop. Res. (1992); 10: 774-783.

21. Takahashi, H., Yang, S., Ueda, Y., Kim, M. and Yamamoto, T. Influence of intact and partially hydrolysed guar gum on iron utilization in rats fed on iron-deficient diets. Compar. Biochem. Physiol. (1994); 109A: 75-82.

22. Hallberg, L. Bioavailability of dietary iron in man. Ann. Rev. Nutr. (1981); 1: 123-147.

23. Reuber, S., Kreuzer, M. and Kirchgessner, M. Interactions of cobalt and iron in absorption and retention. J. trace Elem. Electrolytes Health Dis. (1994); 8: 151-158.

24. Kirchgessner, M. Homeostasis and homeorhesis in trace element metabolism In: Anke, M., Messner, D. and Mills, C.F. eds. Trace Elements in Man and Animals, TEMA (1993); 8: 4-21.

25. Coudray, C., Bellanger, J., Castiglia-Delavaud, C., Rémésy, C., Vermorel, M. and Rayssiguier, Y. Effect of soluble and insoluble dietary fiber supplementation in healthy young men: apparent absorption and balance of calcium, magnesium, iron and zinc. Europ. J. Clin. Nutr. (1997); 51: 375-380.

26. Iqbal, T.H., Lewis, K.0. and Cooper, BT. Phytase activity in the human and rat small intestine. Gut (1994); 35: $1233-1236$.

27. Türk, M., Carlsson, N. and Sandberg, A. Reduction in the levels of phytate during wholemeal bread making; effect of yeast and wheat phytases. J. Cereal. Sci. (1996); 23: 257-264. 